\title{
ANALISIS PENGUNAAN BAMBU PLESTER TERHADAP PENURUNAN BIAYA KONSTRUKSI BANGUNAN DI DUSUN PASSIMBUNGANG KABUPATEN GOWA
}

\author{
ANALYSIS OF THE USE OF BAMBOO PLASTER CONSTRUCTION COST \\ REDUCTION IN DISTRICT KAMPOONG PASSIMBUNGANG GOWA
}

\author{
Meldawati ${ }^{1 *}$, Faris $^{2}$, dan Tahang ${ }^{3}$, Ismail Marzuki ${ }^{4}$ \\ *Email: imelarti@gmail.com \\ ${ }^{1,2,3}$ Program Studi Arsitektur, Fakultas Teknik UNIFA,Makassar \\ ${ }^{4}$ Program Studi Teknik Kimia, Universitas Fajar, Makassar \\ Jl. Prof. Abdurrahman Basalamah No. 101, K.Pos: 90231
}

Submit, 15 Juli 2019; Acepted, 22 September 2019; Published, 30 Oktober 2019

\begin{abstract}
With the emergence of the issue of global warming, which emphasizes the use of environmentally friendly local materials which then give rise to the use of local materials as an alternative, namely bamboo. Gowa regency is largely 'second largest area of bamboo trees in South Sulawesi is 1,600 ha. Passimbungang village, Bajeng western districts, Gowa regency is an area where we can find a lot of bamboo trees but has not been utilized and processed both in society. The purpose of this study was to analyze the comparative efficiency of the use of materials of brick and plaster bamboo material in the construction of public toilets citizens, in addition to the targets to be achieved from this research is to provide new insights in the form of training to the general public how the method of making bamboo plaster. This plaster bamboo research using experimental methods to build a test object such as building public lavatories residents, comparing the results of these tests on the use of materials and the price of bamboo plaster wall construction with brick construction, the exercise period for 8 (eight) months. The result shows a decrease in price by $31.17 \%$ for the use of bamboo wall plaster.
\end{abstract}

Keywords: Bamboo Plaster, construction dindin, Hamlet passimbungang, cost efficiency

\section{ABSTRAK}

Seiring munculnya isu global warming yang lebih menekankan penggunaan material lokal ramah lingkungan yang kemudian memberikan peluang pada penggunaan material-material lokal sebagai alternatifnya yaitu bambu. Kabupaten Gowa merupakan daerah yang memiliki luasan area pohon bambu kedua terbesar di Sulawesi Selatan yaitu sebesar 1.600 ha. Dusun Passimbungang, kecamatan Bajeng Barat, kabupaten Gowa merupakan daerah dimana kita dapat menjumpai banyak pohon bambu namun belum termanfaatkan dan diolah secara baik dalam masyarakat. Tujuan penelitian ini adalah menganalisis perbandingan efisiensi penggunaan material bata dan material bambu plester pada pembangunan WC umum warga, selain itu sasaran yang ingin dicapai dari penelitian ini yaitu untuk memberi wawasan baru berupa pelatihan kepada masyarakat umum bagaimana metode pembuatan bambu plester. Penelitian bambu plester ini menggunakan metode eksperimental dengan membangun benda uji berupa bangunan wc umum warga, hasil pengujian ini membandingkan pada penggunaan jenis material dan harga konstruksi dinding dari bambu plester dengan konstruksi batu bata, jangka waktu pelaksanaan selama 8 (delapan) bulan. Hasilnya didapatkan penurunan harga sebesar 31,17\% untuk penggunaan dinding bambu plester.

Kata kunci : Biaya konstuksi, Bambu Plester, Dusun passimbungang 


\section{PENDAHULUAN}

Pesatnya perkembangnya teknologi dalam bidang struktural mendorong masyarakat untuk tidak lagi menggunakan material lokal seperti kayu dan bambu. Seiring munculnya isu global warming yang lebih menekankan pada konsep bangunan green building yang menggunakan material lokal ramah lingkungan. Hal inilah kemudian memberikan peluang yang baik pada penggunaan material-material lokal sebagai alternatifnya yaitu bambu. Beberapa bangunan di Indonesia mulai menggunakan material bambu sebagai elemen utama bangunannya, selain harga yang terhitung murah, bambu juga mudah didapatkan dimana saja di seluruh wilayah Indonesia.

Misdarti (2004) menuliskan hasil identifikasi Balai Rehabilitasi lahan dan Konservasi Tanah (BRLKT) Wilayah IX, menunjukkan bahwa kabupaten Gowa merupakan daerah yang memiliki luasan area pohon bambu kedua terbesar di Sulawesi Selatan yaitu 1.600 ha setelah Kabupaten Toraja dan Maros. Penelitian ini merupakan bagian dari pengabdian yang dilaksanakan pada dusun Passimbungang, kecamatan Bajeng Barat, kabupaten Gowa. Area ini sangat mudah menjumpai rumpunan bambu yang ditanam di sawah, kebun dan pekarangan rumah masingmasing warga. Rumpun bambu yang ada belum termanfaatkan dan diolah secara baik oleh masyarakat pengolahan bambu hanya sebatas untuk kerajinan anyaman yang digunakan sehari-hari, keterbatasan pengolahan bambu juga disebabkan masyarakat kurang memahami proses pengawetan bambu sehingga bambu dianggap kurang baik untuk digunakan jangka panjang.

Mata pencaharian masyarakat di dusun Passimbungang selain bertani dan berkebun yaitu sebagai pengrajin bata merah sekaligus sebagai tenaga buruh pemasangan bata merah tersebut baik laki-laki maupun perempuan. Namun lamban laun produksi bata merah yang dihasilkan dari pengrajin semakin menurun disebabkan kehabisan bahan baku di daerah mereka sehingga harus membeli dari daerah lain, hal ini juga mengakibatkan harga produksi naik namun tidak diikuti dengan naiknya harga jual dari bata merah.

Tujuan penelitian ini adalah menganalisis perbandingan efisiensi penggunaan material bata dan material bambu plester pada pembangunan WC umum warga dalam upaya pemanfaatan bambu sebagai pengganti bata merah pada konstuksi dinding, selain itu sasaran yang ingin dicapai dari penelitian ini yaitu untuk memberi wawasan baru berupa pelatihan kepada masyarakat umum bagaimana metode pembuatan bambu plester sebagai material alternatif konstruksi bangunan yang ramah lingkungan termasuk proses teknologi pengawetan bambu, yang diharapkan dapat memberi pengetahuan tambahan sekaligus keahlian spesifik dari warga setempat untuk konstruksi bambu pada bangunan.

\section{a. Berdasarkan sejarah dan Karaterisitik}

Konstruksi bambu dalam konstruksi telah digunakan berabad-abad lampau, oleh bangsa Cina menemukan jembatan pengasingan yang menggunakan bambu untuk menyeberangi sungai mereka menciptakan kabel tegangan dengan panjang sampai 120 meter. Di Columbia, jembatan kabel diciptakan dengan menggunakan material bambu yang memiliki kekuatan tarik sampai dengan $3,200 \mathrm{~kg} / \mathrm{cm}^{2}$ untuk jenis Guadua.

Bambu memiliki karakteistik kuat tarik yang sama disepanjang batang, dan kuat tekannya yang terus meningkat sesuai dengan umur bambu, pada bagian luar dari bambu, memiliki kekuatan sekitar empat kali dibandingkan dengan bagian dalamnya, pada bagian luarnyapun mempunyai lapisan yang kedap air. Namun yang perlu mendapat 
perhatian khusus bagian dalam bambu harus dilindungi dari serangan bubuk dan jamur.

\section{b. Jenis Dinding}

Dinding adalah suatu struktur padat yang membatasi dan kadang melindungi suatu area. Tiga jenis utama dinding struktural adalah dinding bangunan, dinding pembatas (boundary), serta dinding penahan (retaining). Dilihat dari macamnya, dinding dapat digolongkan menjadi 3 bagian, yaitu: (1) Dinding Interior, yaitu dinding yang dipakai di dalam ruangan, dapat berupa dinding permanen/dinding massive, dan dinding partisi yang dapat diangkat atau dipindahkan. (2) Dinding Eksterior, adalah dinding yang letaknya di luar ruangan. Karena terletak di luar ruangan maka dinding exterior harus kuat, indah, dan tahan cuaca, (3) Dinding Fungsi Khusus. Dinding fungsi khusus jenisnya disesuaikan dengan fungsi yang harus diembannya. Misalnya dinding kedap suara, tentu dinding tersebut harus terbuat dari bahan akustik yang disesuaikan dengan tingkat ambang kebisingan yang dapat ditoleran.

\section{c. Konstruksi Bambu Plester}

Konstruksi bambu plester merupakan konstruksi dinding yang menggunakan bambu yang dianyaman sasak sebagai rangka menggantikan fungsi bata merah dan rangka bambu dan kemudian diplester. Hasil akhir dari konstruksi dinidng bambu plester ini memiliki ekspresi seperti rumah tembok pada umumnya.

Muliyawan (2014) mengungkapkan konstruksi bambu plester ini dikembangkan dengan beberapa tujuan, yaitu: (1) Pemanfaatan potensi bambu sebagai alternatif material konstruksi yang murah, (2) Material alternatif pengganti bata/batako pada dinding konvensional, (3) Pengawetan dari bambu untuk mengurangi serangan bubuk dan jamur pada bambu, (4) Pengurangan resiko kebakaran pada konstruksi bambu nonplester, (5) Potensi kekuatan tarik bambu sebagai pengganti tulangan besi. Adapun beberapa keunggulan dan kelemahan dari konstruksi bambu plester akan dijabarkan berikut ini.

\section{d. Keunggulannya adalah:}

(a) Konstruksi murah, mudah dan cepat, (b) Kecepatan konstruksi (sekitar 3 minggu dengan 3 orang tukang), (c) Pengurangan resiko kebakaran jika dibandingkan dengan rumah bambu biasa, (d) Pengurangan resiko serangan hama perusak kayu (rayap, bubuk dan jamur), (e) Tidak diperlukan kerapihan anyaman dan sambungan pada bambu karena akan tertutup plesteran, (f) Bahan baku yang mudah didapat, (g) Konstruksi tahan gempa (ringan dan tidak kaku)

\section{Kelemahan adalah:}

(a) Kerapihan anyaman mempengaruhi ketebalan dinding setelah plesteran, (b) Kemungkinan panjang dan ukuran dari bilah bambu yang tidak seragam, (c) Sulit dalam teknik penyambungannya pada proses konstruksi, (d) Masih terlihat retak-retak pada plesteran dinding, jika:

Muai/susut ayaman dan plesteran yang berbeda.

Bambu yang dipakai tidak cukup kering.

Kualitas pasir plesteran yang buruk.

Penurunan tidak merata pada pondasi. 


\section{METODOLOGI}

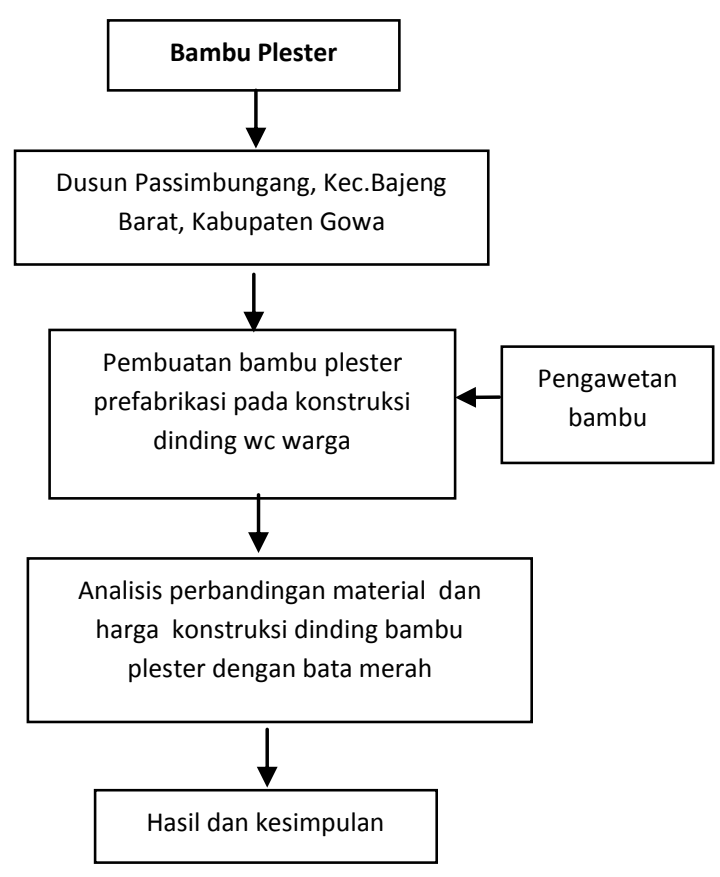

Gambar 1. Diagram alur penelitian

Penelitian bambu plester ini menggunakan metode eksperimental dengan membangun benda uji berupa bangunan wc umum warga di dusun Passimbungang, kecamatan Bajeng Barat, kabupaten Gowa. Dari hasil pengujian ini kemudian membandingkan pada penggunaan jenis material dan harga konstruksi dinding dari bambu plester dengan konstruksi batu bata Adapun jangka waktu pelaksanaan selama 8 (delapan) bulan.

\section{Metode Pelaksanaan}

Pelaksanaan dibagi atas dua tahapan yaitu tahapan pertama proses pengawetan bambu dan tahapan kedua yaitu aplikasi bambu plester pada bangunan wc umum warga. Tahapan Pengawetan bambu ini dilaksanakan di lokasi pembangunan benda uji dengan menyediakan 20 batang bambu utuh kemudian dipotong sesuai ukuran kebutuhan anyaman dinding (1,5 - 3,5 meter) dan siap diisi dengan cairan pengawet bambu. Larutan pengawetan ini mengunakan campuran antara Borax dan Boric, yang dilarutkan ke dalam air (air kurang lebih 20 liter) dengan perbandingan 3:2, konsentrasi maksimum $5 \%$. Khusus dalam penelitian ini kelipatan larutan pengawet yang digunakan yaitu 2 kali dari perbandingan tersebut.

Bambu yang telah terisi cairan pengawet kemudian disandarkan pada dinding rumah yang terlindung dari hujan dan sinar matahari secara langsung pada bagian atasnya. Setelah itu bambu didiamkan selama 2-5 hari hingga bambu berubah warna dari aslinya dan cairan pengawet telah meresap masuk kedalam bamboo dan dapat dikeringkan selama 2 hari tergantung kelembabannya (gambar 2)

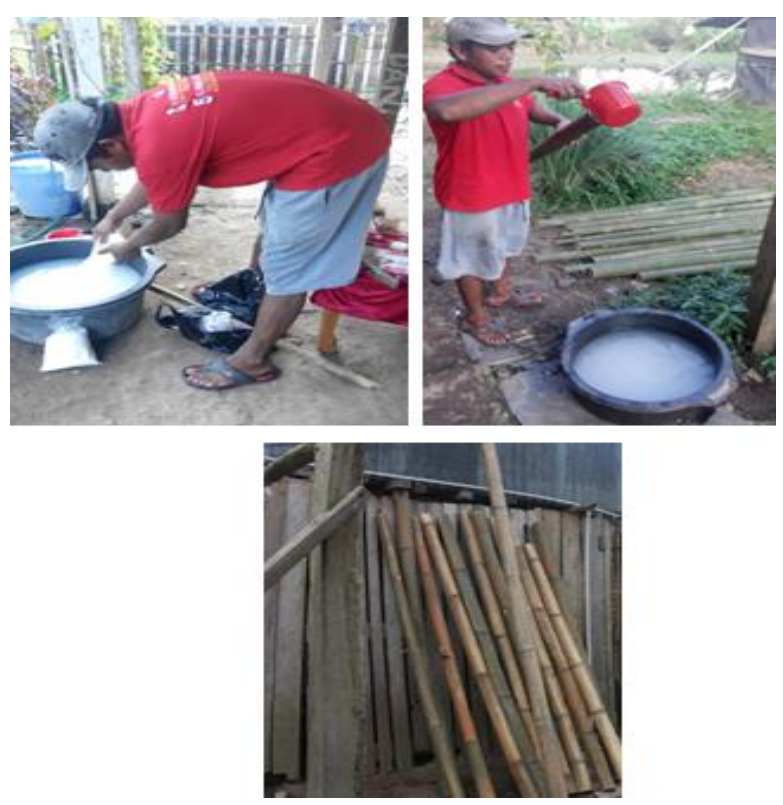

Gambar 2. Proses pengawet bambu

Pembuatan Bambu Plester Prefabrikasi ini mengacu pada metode bambu plester milik Adry Widyowijatnoko dan aplikasinya pada benda uji bangunan yaitu Wc umum warga, tahapannya adalah: (1) batang bambu yang telah diawetkan kemudian dipotong dan dibelah sesuai dengan dimensi dari ketinggian bangunan, bambu dibelah menjadi dua bagian yang sama besar untuk tiang dan balok, sedangkan untuk anyaman batang bambu dibagi menjadi beberapa bagian dengan lebar 2-3 $\mathrm{cm}$. 

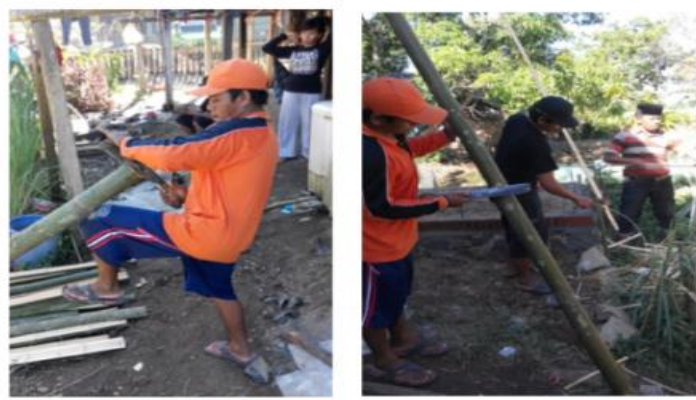

Gambar 3. Proses pemotongan dan pembersihan bambu

(2) Menganyam bambu, bambu yang telah dipotong-potong kemudian dianyam menjadi anyaman sasak, dengan arah horizontal rapat dan bambu vertical berjarak $25-30 \mathrm{~cm}$. (3) Merakit modul dinding bambu, batang bambu untuk kolom diletakkan pada posisinya dengan jarak maksimal $1 \mathrm{~m}$ posisi atas dan bawah saling memunggungi dan menjepit anyaman. Antara batang bambu belah yang saling memunggungi diikat dengan kawat beton rangkap 3 jarak 10$15 \mathrm{~cm}$. Untuk kusen pintu atau jendela dapat dipasang kedalam modul dinding dengan memotong bilah vertical dan horizontal di dalam anyaman sehingga ada lubang pada anyaman sesuai dengan lebar bukaan. Pada kusen pintu ataupun jendela juga dipasangi besi yang rakit kedalam ayaman.
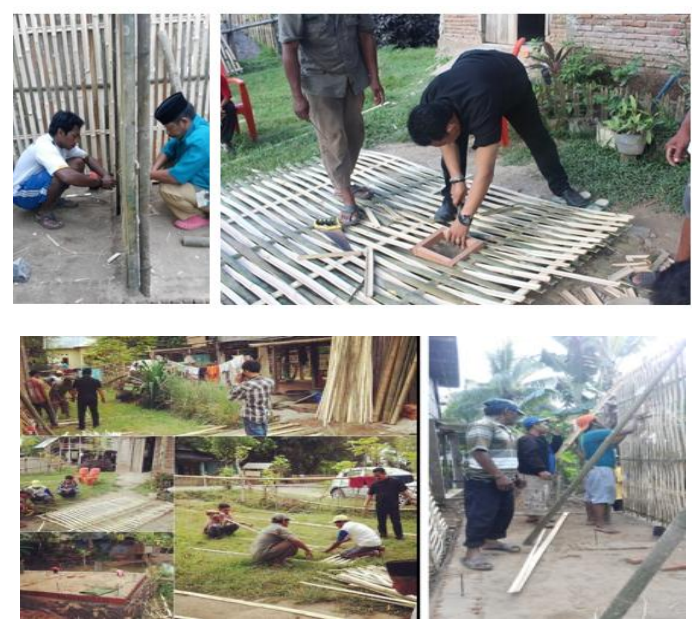

Gambar 4. Proses anyaman bambu plester
(4) Pembuatan pondasi, pondasi rumah bambu plester menggunakan pondasi menerus batu kali. Sloofnya memakai rolaag bata. Pada saat pembuatan sloof, angker harus dipasang untuk diikat dengan anyaman bambu dengan jarak antara angker tidak lebih dari $3 \mathrm{~m}$. (5) Pendirian rumah bambu (Erection), dinding anyaman didirikan dengan kayu sebagai siku penahannya stek diikat dengan kawat ke dinding ataupun panel anyaman. Pertemuan siku dua bidang dinding dapat dilakukan menggunakan tiang bambu yang dibelah, dan disatukan kemudian diikat dengan kawat beton, bilah vertical pada tepi dinding anyaman diikat dengan kolom pada bidang anyaman.
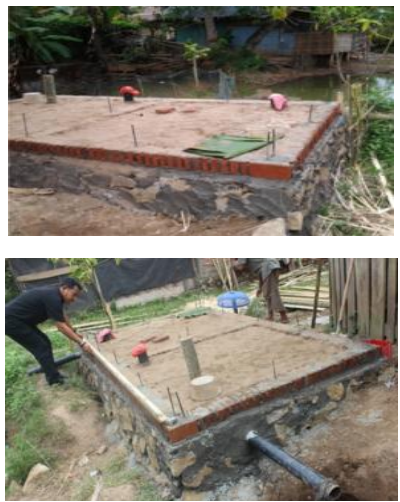

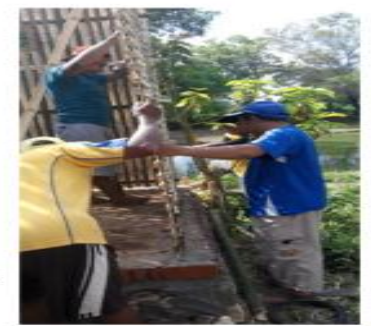

Gambar 5. Pembuatan

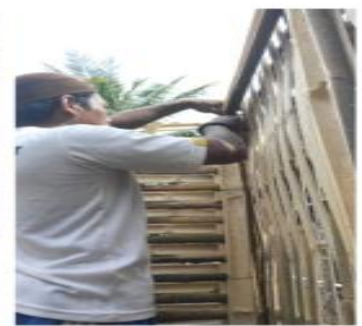

pondasi dan Pemasangan bambu plester
(6) Plesteran dan finishing, pemlesteran dilakukan dengan campuran aduk 1 PC:3 pasir. Pertama-tama dinding anyaman bambu dikomprot terlebih dulu dengan aduk. Pengamprotan pertama tidak boleh terlalu tebal agar dinding jadi tidak terlalu tebal. Setelah aduk kamprot ini telah cukup kering (setelah didiamkan setengah-satu hari) dapat dilakukan pemlesteran kedua untuk meratakan permukaan dinding. Sebelumnya hasil plesteran awal 
dibasahi agar tidak banyak menyerap air yang ada pada campuran plesteran baru. Gunakan roskam untuk meratakan, merapikan, dan menghaluskan permukaan plesteran kedua.

Agar plesteran kolom lurus dipakai papan layaknya bekisting beton dan timbangan dulu dengan lot. Untuk finishing gunakan air kapur yang meresap kedalam retak-retak rambut yang akan timbul pada dinding bambu plester ini semakin lama kapur akan menutup seluruh permukaan dinding.
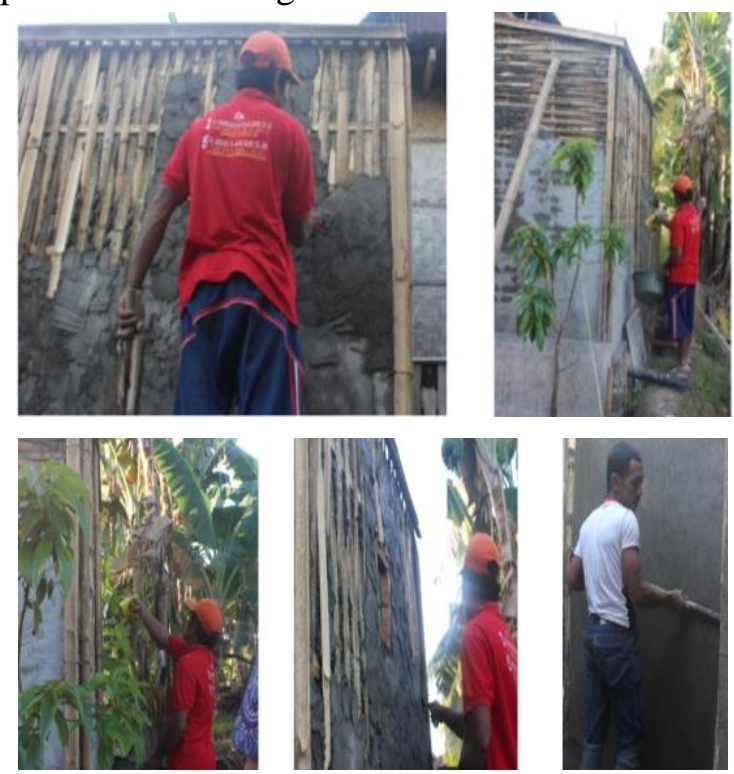

Gambar 6. Proses plesteran dan finishing

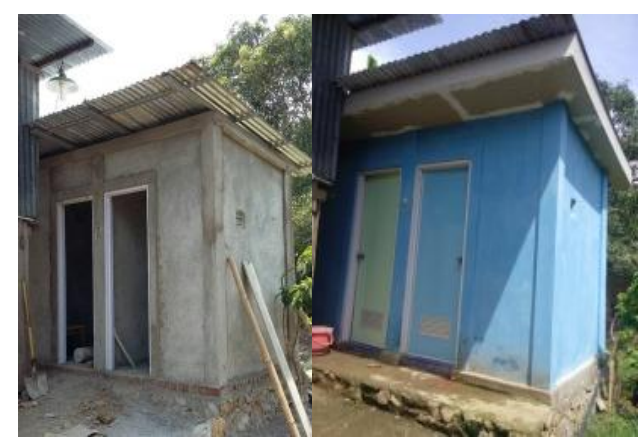

Gambar 6. Hasil akhir konstruksi bambu plester pefabrikasi

\section{HASIL DAN PEMBAHASAN}

Sosialisasi dan penggunaan metode bambu plester bukanlah hal yang baru dan telah banyak dilaksanakan dibeberapa tempat. Perkiraan penekanan biaya produksi dari bangunan yang menggunakan kontruksi bambu plester yang dihasilkan oleh Puslitbang Permukiman mencapai harga Rp. 780.000,- /m2 dan rumah bambu plester yang dibuat oleh Dr. Andry Widyowijatnoko memiliki harga kisaran Rp. $600,000,-/ \mathrm{m} 2$ dibandingkan dengan harga pasaran bangunan dengan material batu sebesar $1.500 .000,-/ \mathrm{m} 2$. Perbandingan persentase harga dapat dilihat pada tabel 1. Penurunan persentase biaya konstruksi yang ada pada tabel 1, juga terlihat dalam hasil yang dicapai pada kegiatan pembangunan konstruksi dinding wc warga dengan luas 4,5 $\mathrm{m}^{2}$, tinggi $2,20-2,50 \mathrm{~m}$ dalam penelitian ini. Adanya penurunan biaya disebabkan efisiensi material yang digunakan hingga terdapat perbedaan harga pada penggunaan konstruksi dinding bambu plester dibandingkan penggunaan bata merah. Perbandingan ini terlihat dalam tabel 2, dalam tabel didapatkan penurunan harga sebesar $31,17 \%$ untuk penggunaan dinding bambu plester.

Tabel 1: Persentase Penurunan harga bangunan menggunakan metode bambu plester dan bangunan umum.

\begin{tabular}{ccc}
\hline Perbandingan & Jumlah (RP) & Persentase \\
produksi & $\begin{array}{c}\text { penurunan } \\
\text { biaya dari } \\
\text { harga pasaran }\end{array}$ \\
\hline Harga pasaran & $1.500 .000 / \mathrm{m} 2$ & \\
material batu & & $52 \%$ \\
\hline Puslitbang & $780.000 / \mathrm{m} 2$ & \\
\hline $\begin{array}{c}\text { Rumah Bambu } \\
\text { Plester oleh Dr. } \\
\text { Andry }\end{array}$ & $600,000 / \mathrm{m} 2$. & $40 \%$ \\
Widyowijatnoko & & \\
\hline
\end{tabular}

Tabel 2: Perbandingan jenis material dan metode yang digunakan 


\begin{tabular}{|c|c|c|c|c|}
\hline \multirow{2}{*}{$\begin{array}{c}\text { Tahapan } \\
\text { Pekerjaan } \\
\text { Konst. } \\
\text { dinding }\end{array}$} & \multicolumn{4}{|c|}{ Perhitungan Harga dan Material } \\
\hline & $\begin{array}{l}\text { Bata } \\
\text { merah }\end{array}$ & $\begin{array}{l}\text { Biaya } \\
\text { (RP) }\end{array}$ & $\begin{array}{l}\text { Bambu } \\
\text { plester }\end{array}$ & $\begin{array}{l}\text { Biaya } \\
\text { (RP) }\end{array}$ \\
\hline \multirow{3}{*}{$\begin{array}{c}\text { Pasangan } \\
\text { Sloef }\end{array}$} & $\begin{array}{c}\text { Besi } \emptyset 10 \\
=4 \mathrm{btg}\end{array}$ & 220.000 & \multirow{2}{*}{$\begin{array}{c}\text { Bata } \\
\text { merah } 120 \\
\text { biji }\end{array}$} & \multirow{2}{*}{48.000} \\
\hline & $\begin{array}{l}\text { Besi } \varnothing \\
6=3 \mathrm{btg}\end{array}$ & 75.000 & & \\
\hline & $\begin{array}{c}\text { Cam } \\
1: 2: 3=0,3 \\
6 \mathrm{~m}^{3}\end{array}$ & 187.832 & $\begin{array}{c}\text { Besi } \emptyset 10 \\
=3 \mathrm{btg}\end{array}$ & 165.000 \\
\hline $\begin{array}{c}\text { Pasangan } \\
\text { Dinding }\end{array}$ & $\begin{array}{c}\text { Bata } \\
\text { merah } \\
3.960 \text { biji }\end{array}$ & 1.584 .000 & $\begin{array}{l}15 \mathrm{btg} \\
\text { bambu }\end{array}$ & 300.000 \\
\hline \multirow{3}{*}{$\begin{array}{c}\text { Pasangan } \\
\text { Kolom }\end{array}$} & $\begin{array}{c}\text { Besi } \varnothing 10 \\
=7 \mathrm{btg}\end{array}$ & 385.000 & \multirow{2}{*}{$\begin{array}{c}3 \mathrm{btg} \\
\text { bambu }\end{array}$} & \multirow{2}{*}{60.000} \\
\hline & $\begin{array}{l}\text { Besi } \varnothing \\
6=6 \mathrm{btg}\end{array}$ & 150.000 & & \\
\hline & $\begin{array}{c}\text { Cam } \\
1: 2: 3=0,4 \\
05 \mathrm{~m}^{3}\end{array}$ & 211.312 & Kawat & 7.000 \\
\hline \multirow{2}{*}{$\begin{array}{l}\text { Pasangan } \\
\text { Ringbalk }\end{array}$} & $\begin{array}{c}\text { Besi } \varnothing 10 \\
=4 \mathrm{btg}\end{array}$ & 220.000 & $\begin{array}{c}2 \text { btg } \\
\text { bambu }\end{array}$ & 40.000 \\
\hline & $\begin{array}{l}\text { Besi } \varnothing \\
6=3 \mathrm{btg}\end{array}$ & 75.000 & Kawat & 3.000 \\
\hline $\begin{array}{c}\text { Plesteran } \\
\text { tebal } 20 \\
\mathrm{~mm}\end{array}$ & $\begin{array}{c}\text { Cam 1:5 } \\
\text { T.15=42,3 } \\
\mathrm{m}^{2}\end{array}$ & 337.444 & $\begin{array}{c}\text { Cam 1:5 } \\
\text { T.20=42,3 } \\
\mathrm{m}^{2}\end{array}$ & 451.160 \\
\hline $\begin{array}{l}\text { Total } \\
\text { harga }\end{array}$ & \multicolumn{2}{|c|}{3.445 .588} & \multicolumn{2}{|c|}{1.074 .160} \\
\hline \multicolumn{3}{|c|}{ Penurunan Harga } & \multicolumn{2}{|c|}{$31,17 \%$} \\
\hline
\end{tabular}

\section{KESIMPULAN}

Metode bambu plester pefabrikasi khusunya pada pekerjaan konstruksi dinding dalam penelitian ini, material yang digunakan lebih sedikit (hanya bambu) dengan waktu pengerjaan yang lebih cepat dari pembangunan yang menggunakan bata merah pada umumnya. Besarnya efisiensi penuruan harga konstruksi dinding menggunakan metode bambu plester yaitu $31,71 \%$.
Kegiatan penelitian ini dalam pelaksanann juga sekaligus memberikan keterampilan khusus bagi masyarakat setempat dalam penggunaan bambu plester pefabrikasi, yang lebih mudah, praktis dan ekonomis secara berkelanjutan di masyarakat luas. Terlaksananya kegiatan ini tidak lepas dari bantuan berbagai pihak untuk itu ucapan terima kasih kepada masyarakat serta aparat pemerintahan dusun Passimbungan, pendanaan dari DIKTI untuk skim IPTEKS bagi Masyarakat (IbM), serta Kopertis Wilayah IX.

\section{Referensi}

Muliawan, I Wayan, (2014), Aplikasi Teknologi Bambu Semen Sebagai Dinding Di Desa Penglipuran Kabupaten Bangli, Paduraksa, Volume 3 Nomor 1.

Kosasih, Dahlan.,(2006), Arsitektur dan konstruksi Bambu Oleh Oscar Hidalgo, Departemen Teknik Sipil

Widyowijatnoko, A., 1999, Kajian Konstruksi Bambu Plester dan Konsep Pengembangannya, Departement Teknik Arsitektur ITB.

Widyowijatnoko, A, (2008), Prefabricated Low Cost Housing Bamboo Reinforcement and Appropriate Technology, in Modern Bamboo Structures - Xiao et al. (eds), Taylor Francis Group. London, ISBN 978-0-415-47587-6.

https://lincakgentan.wordpress.com/2010/03/23/peng awetan-bambu-cara-pak-morisco/, diakses 03 juni 2015

www.bamboocentral.org/PDF.../MODUL_PELATIH AN_MABUTER,di akses juli 2015. 